TEMAS DE ACTUALIDAD Rev Chil Salud Pública 2014; Vol 18 (1): 11-14

\section{DILIGENCIA UNIVERSITARIA}

Miguel Kottow

Escuela de Salud Pública Facultad de Medicina Universidad de Chile mhkottow@gmail.com
Con ocasión de ser dirimido el Concurso Juvenal Hernández 2013, de la Universidad de Chile 1 , refulge la figura del rector que invistiera, después de Andrés Bello, el rectorado más prolongado de la Universidad (19331953). Momentos importantes de destacar considerando la relevancia social y política que el tema educación ha tenido en recientes años, así como el dato de que en 2014 han de renovarse los más altos cargos directivos de la Universidad, a nivel de rectorado y decanatos. Estos actos eleccionarios cobran especial interés por cuanto las movilizaciones masivas determinaron el compromiso político de reformular la educación chilena en todos sus niveles, fundamentalmente a lo largo de dos ejes programáticos: gratuidad y calidad. Ocupando un lugar prominente en las propuestas políticas presidenciales y parlamentarias, se anticipa un debate trascendente acerca de la educación, que será escudriñado con detención por los movimientos sociales; los poderes del Estado serán llamados a rendición de cuentas en un ambiente de irritabilidad e impaciencia que augura turbulencias sociales no menores.

En esta atmósfera de exigencias y expectativas, la Universidad de Chile será un campo electoral donde candidatos a la Rectoría y a Decanatos tan importantes como el de nuestra Facultad de Medicina, no podrán dejar de abordar el tema económico y el de la calidad, dejando en claro que ambos son interdependientes en lo pragmático, mas no en lo conceptual: sin una economía equilibrada es difícil convocar a los mejores y estimular su compromiso, porque la academia está en el mercado, donde distracciones y ofertantes son poderosos. Pero sin calidad no hay viabilidad económica, puesto que también aquí juega con fuerza la competitividad inmisericorde.

1. Entre los favorecidos: Miguel Kottow, "Una mirada latinoamericana a la salud pública”, texto elaborado como académico de la Escuela de Salud Pública y con su apoyo, actualmente en prensa. 
Los académicos de la Universidad comprometieron una deuda al apoyar el llamado estudiantil a la calidad, pero sin hacer lo suyo para reflexionar sobre el tema y "exiliarse del exilio" en que los había puesto la "música" orquestada por la dictadura. "La calle" abrió los apetitos sin que la academia se dispusiera a proporcionar los nutrientes. Reconocen su ausencia los propios académicos, la acusan los estudiantes, y lo hace ver la prensa desde su óptica política y tecno-económica: bajo el titular editorial "Temas económicos", el acápite subtitulado "La insuficiencia del análisis académico", concluye reclamando que "[L]as universidades están llamadas a conformar cuerpos académicos amplios y de excelencia, no aislados de las necesidades del país, ni atrincherados en la batalla de las ideas" ( $E l$ Mercurio, 4.01.2014, p. 3). Sin duda, quien dirige una institución debe ser un buen contador, pero le corresponde determinar lo que se entenderá por bueno.

Con cierta intranquilidad, se observan brotes de asambleísmo que pretenden no solo convocar a la discusión abierta y democrática, cosa loable y a destacar, sino además generar un ambiente de participación efectiva en la toma de resoluciones y decisiones. Medir la temperatura y pulsar la opinión académica es materia de arquitectura y filigrana; requiere pasar de consignas a programas, de difusas alocuciones a concretas presentaciones de agendas y equipos de trabajo, crecer de promesas a compromisos vinculantes. Es trabajo de pequeño grupo y extensión transparente.

Pensar la Universidad en serio es rehuir la altisonancia. Al dejar la rectoría en 1953, Juvenal Hernández señaló: "Lo que se ha dado en llamar 'la misión de la Universidad' es algo que aún permanece en pie con dos formidables signos de interrogación para sabios y humanistas". Lo dijo en más de un ocasión, y no fue el único. La misión de la Universidad es una nebulosa, una entelequia, un concepto tan expansivo que todo lo alberga sin precisión, navegable para astutamente capear resistencias, exigencias, protestas. La Universidad no tiene misión, tiene tareas. ¿ $¿[\mathrm{~A}]$ spiraciones reformistas" en las universidades? no: "reformarse a sí mismas en un constante proceso de autocrítica" pedía el rector Gómez al hablar de la "Universidad en nuestro tiempo". Y don Jorge Millas se declaraba "alarma[do]... por la superficialidad con que en lugares del poder público, y en grupos generados por éste en el interior de las universidades, se da respuesta a cuestiones difíciles”.

Seguir hablando genéricamente de calidad en la educación superior es quedar atrapado en arenas movedizas, en que los movimientos mínimos aceleran el hundimiento. Más importante es señalizar los cuatro caminos por los cuales la Universidad debe ser encauzada por timoneles premunidos de mapa, brújula y, si fuese necesario, astrolabio: rol del Estado, profesionalismo, humanidades, regionalidad. No son temas nuevos, en su largo rectorado Juvenal Hernández los abordó en más de una ocasión; pertinente es recordar también algo de lo dicho por su maestro, Enrique Molina Garmendia, y por su sucesor inmediato, Juan Gómez Millas.

\section{EL ESTADO: EDUCACIÓN PÚBLICA Y EDUCACIÓN PRIVADA}

Decía Andrés Bello al fundarse la Universidad de Chile: “Todas las sendas en que se propone dirigir las investigaciones de sus miembros, el estudio de sus alumnos, convergen a un centro: la Patria”. Como primera acepción, la preposición "de" significa posesión o pertenencia, solo en segunda instancia proveniencia. No es frecuente que las universidades estatales reconozcan, sin ambages, que son de su Estado: hablan de universidad autónoma, nacional, de lugar, adjetivan lo que nuestra Universidad declara directamente: es de Chile. Así se entendió la fundación de la Universidad de Chile, y del mismo modo lo vio Enrique Molina, fundador y primer Rector de la Universidad de Concepción: "No concebíamos [...] que la Universidad pudiera existir de otra manera que fundada por el Estado". No de otro modo lo entendía el rector Hernández: "Frente a la iglesia docente que primara en el período colonial, la ley coloca la educación al amparo del Estado y bajo tutela de la Universidad". 
Lo que hoy nos tiene tan inquietos, no preocupaba mayormente al rector Hernández cuando celebraba el centenario de la Universidad: "No estamos en contra de la enseñanza particular. Por el contrario, consideramos que ella no es solo útil sino necesaria en un país pobre, en que las sumas asignadas al Presupuesto de Educación son de todo punto insuficientes para atender las exigencias cada vez más dramáticas de nuestro medio nacional".

"La Universidad, que no tiene, por ahora, hogares universitarios propios, recurre a dos instituciones de asistencia económica: la liberación del pago de los derechos de matrícula y la concesión de becas. Extraordinariamente, la Universidad costea, en pensionados privados, la permanencia en Santiago de estudiantes distinguidos de provincia, de ambos sexos". Parece cuento de viejos cuando, los que lo somos, recordamos haber transitado sin costo por la educación escolar y la universitaria.

\section{PROFESIONALISMO}

Enrique Molina a los 25 años de la Universidad de Concepción: "Las universidades deben ofrecer el más bello ejemplo de fundición armónica del trabajo espiritual y material. Sabemos que el ritmo del progreso ético-espiritual de la humanidad no ha podido acompasarse al de su progreso técnico. A las universidades corresponde la salvadora tarea de restablecer este equilibrio y mantenerlo".

"Alguna vez se ha formulado a la Universidad el cargo que sólo 'instruye' y no 'educa', afirmación que no es realidad muy exacta”. Mas tampoco es errado: "En nuestra enseñanza ha dominado como base fundamental de los estudios el aspecto profesional de tradición napoleónica; estamos absorbidos por el pragmatismo y hemos dejado sin estímulo el alma de la Universidad, esto es, el incansable anhelo de descubrir e investigar".

Y en otra ocasión: "El graduado universitario no debe salir de las aulas armado con la simple y mañosa habilidad de un rábula o de un curandero y que la preparación profesional de que ha sido objeto envuelve una verda- dera forma de cultura. Sería ésta incompleta si además el graduado no saliera penetrado de un sentido profundo de la ética de su profesión".

"La constatación de que la época moderna, en todos los aspectos de la cultura, ha sido marcada por una tensión creciente, entre la visión científica del hombre y la visión humanista tradicional, me ha hecho llegar a la conclusión que reconciliar esas visiones es una tarea urgente en que todos debemos participar”.

\section{HUMANIDADES}

"A las universidades corresponde, en gran parte, salvar y saber conservar los valores éticos y jurídicos que la humanidad indudablemente posee, y estudiar las nuevas formas de vida que las necesidades de la época reclaman, de manera que, sin destruir lo bueno que tenemos, se puede crear para los hombres un mundo mejor".

"La estabilidad y el progreso moral, social y político de una democracia moderna dependen de la difusión de su cultura, y el amor patrio y el civismo verdaderos deben cimentarse sobre un entusiasmo inspirado por la universalización del saber".

"Humanistas y tecnólogos con frecuencia han opuesto la educación humanista a la educación técnica, como si entre ellas hubiese una auténtica oposición".

Apoyado en el testimonio de la Universidad de Rangoon, escribía Gómez Millas: "No es suficiente decir que la investigación desinteresada es la única función de la Universidad y que en cambio no lo es la de enseñar a los estudiantes a fabricar fósforos y jabón. La respuesta inevitable... ¿qué debemos enseñar, cómo hacerlo y con qué objetivos?”. Profesor, mas no rector, de la Universidad, escribía Jorge Millas: "Pues ellas [las universidades] adiestran a los futuros panaderos del pan cotidiano, sirven también para renovar periódicamente las reservas de aquellas formas de nutrición humana relacionadas con el conocimiento, y por no ser el pan mínimo del panadero, están más allá de los mercados”. 
"El problema del crecimiento de la universidad es diferente en los países de viejas tradiciones científicas y culturales al de aquellos otros donde se producen rápidos procesos de descolonización y la vida universitaria carece de raíces regionales y vegeta en la rutina”. [...] "El más grave conflicto -recalca Gómez Millas- se presenta cuando los países que la desean deben, al mismo tiempo, salvaguardar su independencia o algunas de sus valiosas tradiciones culturales".

\section{RONDAN LOS FANTASMAS}

Iconografía a página completa en una historia de la universidad chilena (1990): "Augusto Pinochet Ugarte (n. 1915), Presidente de la República (1974-1990). Bajo su gobierno se puso fin a la politización de las universidades y se inició su segunda recuperación”.

"Pero la Universidad de Chile, como asimismo las demás universidades que existen en el país, perdieron, en los últimos años, la brújula de su destino... por sobre las cenizas de ese incendio, alumbró siempre una llama desconocida que ha hecho posible el renacimiento del espíritu universitario, bajo la dirección de las actuales autoridades. Se han restablecido la paz, el orden y el respeto a las jerarquías”. Dicho en 1978 por Juvenal Hernández. Más hubiera valido el silencio...

Nunca rector de universidad, pero siempre rector de mentes, Jorge Millas preguntaba, en voz alta, en 1981: “¿Delenda est universitas?”: "La Universidad de Chile -tomando apenas uno, entre varios ejemplos-, necesitó solo un rector para inspirar y dirigir la expansión y modernización ocurridas entre 1932(3) y 1953. Dicho rector, profesor de Derecho Romano, se llamó Juvenal Hernández y fue reelegido tres veces por sus pares. Lo sucedió otro académico, también elegido y reelegido por un período total de diez años -nuestro educador y maestro de historiadores, Juan Gomez (sic) Millas, bajo cuyo impulso tuvo lugar una readecuación notable de la investigación científica en la Universidad... [El] desorden aqueja gravemente a nuestras universidades en la hora actual. Por compuestas que se hallen exteriormente, su espíritu está postrado. Su quietud no es auténtica: no es la de la reflexión y el estudio, harto necesaria, cuando es verdadera. Es la quietud -más bien inmovilidad-del temor y de la inseguridad consiguiente".

"No podía la Universidad mantenerse aislada de su ambiente para vivir una existencia de puras abstracciones, porque el grupo social seguía su evolución, y los elementos integrantes, al no renovarse, se sumergen en la inercia regresiva y mueren en la esterilidad".

Citas. Entremezcladas. Sin fuentes bibliográficas. ¿Para qué? Quienes piensen postular a ocupar los altos cargos cuyo mandato se renueva, conocen estos documentos, conocen lo que la Universidad ha sabido pensar y decir, conocen el peso de quienes los han precedido y saben, también, lo que se requiere: Little brother is watching, también lee y reflexiona.

Reencantar la Universidad de Chile. Una universidad del Estado, para la sociedad. Menos mercado y más profesionales resistentes a las configuraciones empresariales, al negocio académico. Menos rigor sistemático, disponer más espacios de reflexión. Menos enroques reformistas, más Weber -racionalidad instrumental y racionalidad de valores-, más Habermas -menos razón instrumental, más razón comunicativa y emancipadora-.

¡Ahora! Antes que suenen las campanadas de medianoche. 